\title{
Hyponatremia: A Clinical and Practical Approach
}

\author{
Varun KM Dhara
}

\begin{abstract}
Hyponatremia is a frequent trouble encountered in patients manifesting with unfocused features. The etiology can be multiple, and diagnosis of each cause is demanding. Hyponatremia may be euvolemic, hypovolemic, or hypervolemic. Appropriate analysis of a variety of laboratory investigations helps distinguish the various types of hyponatremia. Management differs with the character of start, whether it is acute or chronic, severity and features.
\end{abstract}

Keywords: Critical care, Electrolytes, Hyponatremia.

Annals of SBV (2020): 10.5005/jp-journals-10085-8113

\section{INTRODUCTION}

Hyponatremia is defined as a serum sodium $<135 \mathrm{mEq} / \mathrm{L} .{ }^{1}$ This condition is a chronic and constant nightmare to clinicians and pathologists due to its varied or broader etiopathogenesis. Multiple etiologies and variety of symptoms make it a puzzle which cannot be solved easily. Varying and ever-changing guidelines did not help the cause. These articles pave light to the disorder and its management. Hyponatremia is the electrolyte disorder typically present in day-to-day life of physician, with a stated occurrence of 15-30\%. ${ }^{2}$ It creates substantial diagnostic and management trouble for clinicians. This state has many reasons and influencing factors. The important and immediate attention should be given for the prompt and correct identification of the reason and its management. In the delicate setting, management frequently has to be started before an optimistic judgment can be made and results of helpful biochemical investigations are obtainable. Both over treatment and under treatment can create overwhelming effects on cerebral function. ${ }^{3}$

A frequent clinical problem, hyponatremia commonly increases in hospitalized patients. Although morbidity varies extensively in severity, grave problems can occur from the disorder itself as well as from mistake in management. ${ }^{4}$

\section{Materials and Methods}

The review article was searched based on MESH terms, hyponatremia, causes, pathogenesis, and management. The data search was extensively done on PubMed, Google scholar, and Google sites.

\section{Prevalence}

Hyponatremia (serum sodium level $<135 \mathrm{mEq} / \mathrm{L}$ ) is the most frequent electrolyte defect in hospitalized patients with the stated occurrence in range $5 \%$ to almost $35 \%$ in foreign countries. ${ }^{5,6}$

Increased mortality, duration of hospital stay, and emerging of complications are unknown implications of hyponatremia. ${ }^{7,8}$

\section{Causes of Hyponatremia ${ }^{9-11}$}

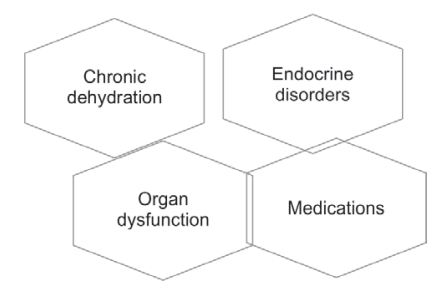

Department of Internal Medicine, Shri Sathya Sai Medical College and Research Institute, Kancheepuram, Tamil Nadu, India

Corresponding Author: Varun KM Dhara, Department of Internal Medicine, Shri Satya Sai Medical College and Research Institute, Kancheepuram, Tamil Nadu, India, Phone: +91 08247758398, e-mail: varun.dhara31@gmail.com

How to cite this article: Dhara VKM, Hyponatremia: A Clinical and Practical Approach. Ann SBV 2020;9(1):17-21.

Source of support: Nil

Conflict of interest: None

\section{Medications}

Diuretics, antidepressants, opioids, and drug-ecstasy.

\section{Endocrine Disorders}

Hypothyroidism and hypocortisolism, SIADH (syndrome of inappropriate ADH secretion), and Addison's disease.

\section{Organ Dysfunction}

Heart failure, kidney, and liver diseases.

\section{Excessive Diuretic Therapy}

Hyponatremia as such can be categorized based on the volume of body fluid, low, normal, and high volume. Low happens when something happens leading to loss of body fluid. Circumstances that can guide to incorrectly low sodium measurements elevated blood sugar, protein, and deranged lipid profile. ${ }^{11-13}$

\section{Symptoms of Hyponatremia ${ }^{11,14}$}

Acute hyponatremia has a typical start of symptoms in less than 48 hours. Patients build up neurological features causing from cerebral edema causing seizures, altered mentation leading to coma, and death.

\section{Chronic Hyponatremia}

Hyponatremia just beginning over $>48$ hours. Major chunk of patient population is suffering from this. The serum sodium concentration is usually above $120 \mathrm{mEq} / \mathrm{L}$. There is a protective adaptive mechanism of brain to reduce the degree of cerebral edema. Hence, in chronic hyponatremia, patients may appear

(0) The Author(s). 2020 Open Access This article is distributed under the terms of the Creative Commons Attribution 4.0 International License (https://creativecommons. org/licenses/by-nc/4.0/), which permits unrestricted use, distribution, and non-commercial reproduction in any medium, provided you give appropriate credit to the original author(s) and the source, provide a link to the Creative Commons license, and indicate if changes were made. The Creative Commons Public Domain Dedication waiver (http://creativecommons.org/publicdomain/zero/1.0/) applies to the data made available in this article, unless otherwise stated. 
symptom less. Mild hyponatremia can cause vague nausea vomiting, and rarely subclinical neurologic defect may be present when the serum sodium is between $120 \mathrm{mEq} / \mathrm{L}$ and $130 \mathrm{mEq} / \mathrm{L}$. Hyponatremia in the elder person may be obviously visible with recurrent falls and gait instabilities.

Hyponatremia is divided as pseudohyponatremia, true and translocational hyponatremia.

Normal serum osmolality is $280-295 \mathrm{mOsm} / \mathrm{kg}$. Pseudohyponatremia is due to hypertriglyceridemia or multiple myeloma. In regular subjects, the plasma water is $93 \%$ of the plasma volume. Plasma water part falls lower than $80 \%$ in cases with noticeable hyperlipidemia (triglycerides $>1500 \mathrm{mg} / \mathrm{dL}$ ) or hyperproteinemia (protein $>10 \mathrm{mg} / \mathrm{dL}$ ). ${ }^{15}$ Rise in blood urea causes the hyponatremia in renal failure. ${ }^{16}$

True hyponatremia is having a fall in serum osmolality and is divided into hypervolemic, hypovolemic, and euvolemic based on volume status. ${ }^{17-19}$
Mineralocorticoid deficit is another main reason of hypovolemic hyponatremia and may be connected with hyperkalemia. ${ }^{22}$

\section{Euvolemic Hyponatremia}

Sixty percent of case population has this type of hyponatremia. The usual reason of euvolemic hyponatremia is SIADH. ${ }^{10}$

\section{Hypervolemic Hyponatremia ${ }^{23}$}

The main causes included are congestive cardiac failure, cirrhosis, and nephritic syndrome. In these cases, sodium in the body is augmented, but total body water (intracellular and extracellular fluid) is unreasonably extended leading to hyponatremia and edema. ${ }^{24}$ Hyponatremia linked with CCF may also be exacerbating by diuretics management. Many studies have showed that the growth of hyponatremia in this state will have worsened prognosis. ${ }^{23,26}$

\section{Types of Hyponatremia ${ }^{12}$}

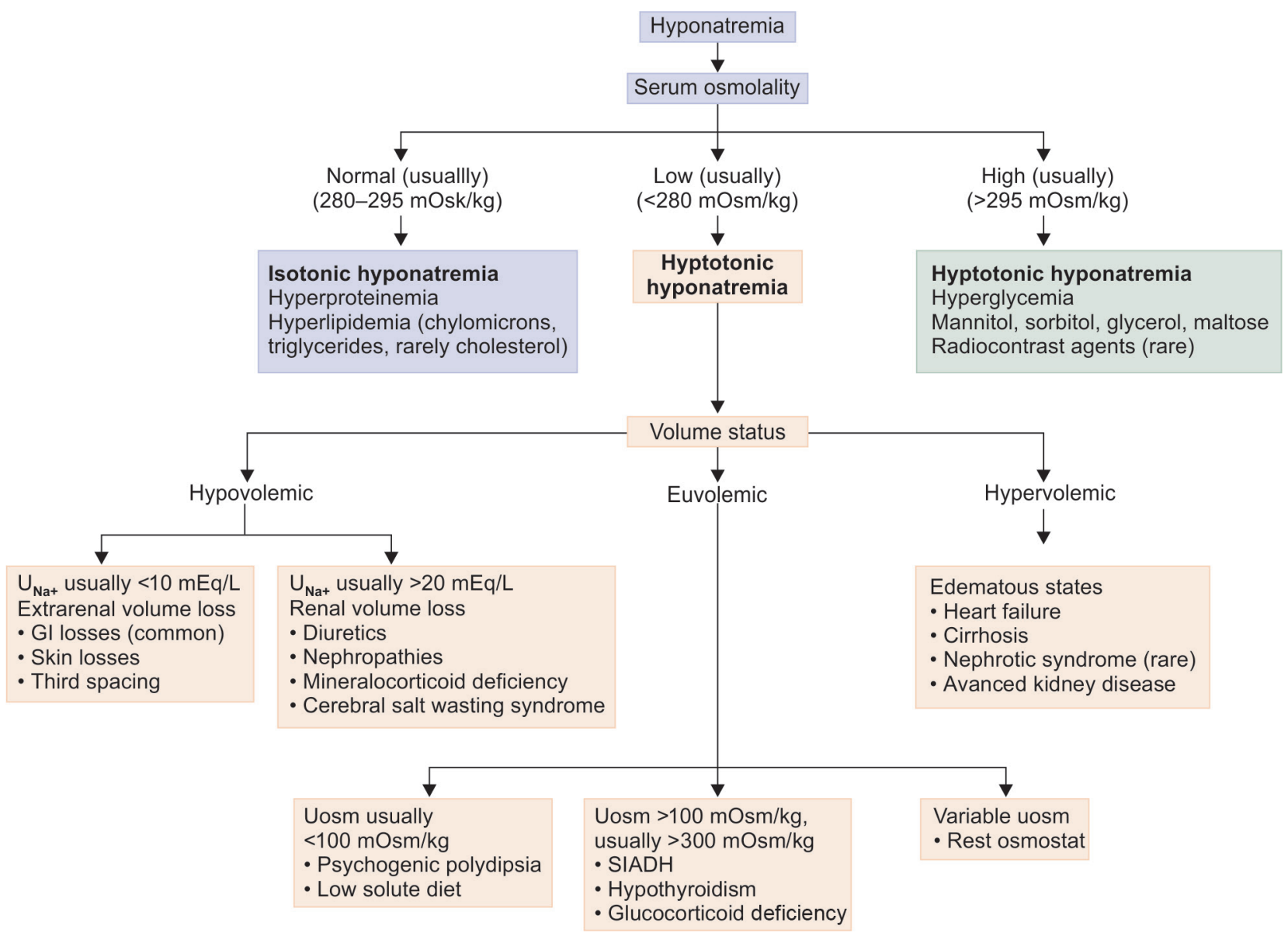

\section{Hypovolemic Hyponatremia}

Reduction in plasma volume may be secondary to renal cause or nonrenal cause. ${ }^{20,25}$ Diuretic-persuaded hyponatremia is common with thiazide diuretics, and usually it begins soon after commencement of drug, may be serious, and is frequent in elder female gender. ${ }^{21}$

\section{Management of Hyponatremia}

The management of hyponatremia depended mainly on its commencement, etiology, and symptomatology. Early assessment of any patient with hyponatremia engages in recognition of the start of the state (acute or chronic), the occurrence of features, and evaluation of quantity grade. A previous analysis of disease of liver, 
kidney, and heart has to be seen, as well as earlier electrolytes to differentiate acute from chronic hyponatremia. Any blood loss or extracellular fluid should be identified. An exact drug history and history of signs of headache, nausea, seizures, and confusion, which point to raised intracranial pressure should be noted. On physical examination, a precise measurement of the patient's volume status is significant.

Measurement or investigation of ${ }^{27-31}$

- Serum osmolality,

- Urine osmolality,

- Urine sodium,

- Serum sodium,

- Urine to serum electrolyte ratio,

- Fractional excretion of sodium,

- Serum uric acid and urea concentrations,

- Acid-base and potassium balance,

- Saline infusion,

- Thyroid investigations, adrenal stimulation tests, CT/MRI brain, and imaging of chest.

Each investigation will be needed to differentiate the different types of hyponatremia.

The treatment of hyponatremia will be based on the volume status, length of hyponatremia (whether acute less than or equal to 48 hour or chronic more than 48 hours), presence or absence of symptoms, and cause of hyponatremia. ${ }^{32,33}$

\section{Studies Related to Hyponatremia (TABLE 1)}

Elderly patients in USA were included in a study on their demographic profile with regards to hyponatremia and it showed that SIADH, diuretics, and SSRIs were common causes and it had significant age-related morbidity and mortality. ${ }^{34}$

In a study done in India among patients staying in hospital, confusion, headache, and tiredness were the most frequent symptoms, of them two patients had seizures, and $20 \%$ patients showed no symptoms. Nausea was significantly more frequent in patients with hyponatremia. Twenty-two patients (31.4\%) had hyponatremia during their stay in the hospital. Most had multiple causative factors, reduced eating being the most common (82.9\%), followed by augmented losses of blood (65.7\%), and various factors (70.0\%). Drugs, fluid excess, and unsuitable Ryle's tube feeds more usually precipitated hyponatremia in patients. ${ }^{35}$

Shapiro et al. did a study which was done for about 5 months in the medicine wards. Eighty-six patients aged more than 65 years with serum sodium levels less than or equal to $125 \mathrm{mEq} / \mathrm{L}$ were incorporated. The occurrence of hyponatremia was $6.2 \%$. The frequent reason of hyponatremia was the syndrome of inappropriate antidiuretic hormone secretion (SIADH) causing euvolemic hyponatremia. ${ }^{36}$

A study was conducted among patients in hospital and found the result of severe hyponatremia with regards to mortality and duration of hospital stay, on the whole death, was $27 \%$ in hyponatremic patients in comparison to $9 \%$ in nonhyponatremic patients, and length of admission was longer in hyponatremic patients. $^{37}$

In a study, patients who had severe hyponatremia were evaluated in comparison with patients who gained severe hyponatremia in a 3-month hospital stay. In hospital-gained hyponatremia, treatment started significantly later and the
Table 1: Studies showing hyponatremia, causes, and treatment

\begin{tabular}{|c|c|c|}
\hline Study & Year & Findings \\
\hline Kutz A et al. & 2020 & $\begin{array}{l}\text { Occurrence of hyponatremia was highest } \\
\text { during summer season and as directly } \\
\text { correlating with outdoor temperature, and } \\
\text { in their population, it showed a higher } \\
\text { female preponderance. }\end{array}$ \\
\hline $\begin{array}{l}\text { Alessandro } \\
\text { Peri }\end{array}$ & 2019 & $\begin{array}{l}\text { Vaptans are very useful in maintaining } \\
\text { the serum sodium levels even after early } \\
\text { correction and discharge of the patient from } \\
\text { the hospital. }\end{array}$ \\
\hline Ganguli et al. & 2015 & $\begin{array}{l}\text { Initial hyponatremia was seen in } 8.71 \% \\
(n=53) \text { and } 4.1 \%(n=25) \text { had chronic hy- } \\
\text { ponatremia in the study population. } \\
\text { The major causes of hyponatremia included } \\
\text { SIADH and thiazide diuretics, and SSRIs. }\end{array}$ \\
\hline Agarwal et al. & 2011 & $\begin{array}{l}\text { Nausea was significantly more frequent } \\
\text { in patients with hyponatremia. } 31.4 \% \text { had } \\
\text { hyponatremia during their stay in the } \\
\text { hospital. Drugs, fluid excess, and unsuitable } \\
\text { Ryle's tube feeds more usually precipitated } \\
\text { hyponatremia in in patients. }\end{array}$ \\
\hline
\end{tabular}

Shapiro et al. 2010 The prevalence of hyponatremia was $6.2 \%$ (8.1\% female and $4.0 \%$ male). The frequent reason of hyponatremia was the syndrome of inappropriate antidiuretic hormone secretion (SIADH), whose cause could be found in only $46 \%$ of cases.

Gill et al. 2006 Mortality and duration of hospital stay were more in hyponatremic patients when compared to normonatremic patients.

Hoorn et al. 2006 At admission, hyponatremia had better detection and early correction when compared to hospital stay-gained hyponatremia, and it was directly proportional to duration of hospital stay.

Annane et al. 2009 Oral conivaptan was safe and effective in hyponatremia (euvolemic and hypervolemic).

Gerbes et al. 2003 An orally active vasopressin receptor antagonist can correct hyponatremia in patients with cirrhosis and ascites.

duration of hospitalization was longer. Factors that added to hospital-gained hyponatremia incorporated: thiazide diuretics, drugs stimulating antidiuretic hormone, surgery, and hypotonic intravenous fluids. ${ }^{38}$

In a study done on occurrence of hyponatremia with seasonal variations as a primary outcome, it showed raised occurrence of hyponatremia during summer when the outdoor temperatures were highest and especially prevalent in elderly female patients. ${ }^{39}$

\section{Studies Related to Management of Hyponatremia}

In a study with oral conivaptan, a V1A/V2-receptor antagonist, 83 patients with serum [Na] less than $130 \mathrm{mEq} / \mathrm{L}$ were randomly assigned to placebo or conivaptan 40 or $80 \mathrm{mg} /$ day for 5 days. Oral conivaptan was efficient in rising serum sodium and it had greatest effect on euvolemic hyponatremia. ${ }^{40}$

In a study, the effects of VPA-985, an orally active vasopressin V2 receptor antagonist, in patients with cirrhosis and dilutional 
hyponatremia were investigated. Normalization of serum sodium concentration was attained in $27 \%$ and $50 \%$ of patients in the VPA-985 $100 \mathrm{mg} /$ day and $200 \mathrm{mg} /$ day groups, respectively, but in none of the patients in the placebo group. ${ }^{41}$

In an analysis done by Alessandro Peri, he has stated that concurring with previous trails, vaptans had an ability to maintain serum sodium level post discharge from hospital, which have been diagnosed and corrected as euvolemic and hypervolemic hyponatremia. $^{42}$

\section{SUMMARY}

The correct diagnosis and cause of hyponatremia are essential in management of patients particularly hospitalized patients. The electrolyte imbalance if correctly diagnosed and treated can avoid mortality and reduce morbidity. Normal saline outlines the root of management for hypovolemic hyponatremia, while $3 \% \mathrm{NaCl}$ and fluid limit are important for euvolemic hyponatremia. Hypervolemic hyponatremia responds well to fluid constraint and diuretic drugs.

\section{References}

1. Verbalis JG, Goldsmith SR, Greenberg A, et al. Diagnosis, evaluation, and treatment of hyponatremia: expert panel recommendations. Am J Med 2013;126(10 Suppl 1):S1-S42.

2. Reynolds RM, Seckl JR. Hyponatraemia for the clinical endocrinologist. Clin Endocrinol (Oxf) 2005;63(4):366-374. DOI: 10.1111/j.13652265.2005.02318.x.

3. Sterns RH, Cappuccio JD, Silver SM, Cohen EP. Neurologic sequelae after treatment of severe hyponatremia: a multicenter perspective. J Am Soc Nephrol JASN 1994;4(8):1522-1530.

4. Upadhyay A, Jaber BL, Madias NE. Epidemiology of hyponatremia. Semin Nephrol 2009;29(3):227-238. DOI: 10.1016/j. semnephrol.2009.03.004.

5. Burst V. Etiology and epidemiology of hyponatremia. Disord Fluid Electrolyte Metab 2019;52:24-35. DOI: 10.1159/000493234.

6. Anderson RJ. Hyponatremia: a prospective analysis of its epidemiology and the pathogenetic role of vasopressin. Ann Intern Med 1985;102(2):164. DOI: 10.7326/0003-4819-102-2-164.

7. Hao J, LiY, Zhang X, Pang C, Wang Y, Nigwekar SU, et al. The prevalence and mortality of hyponatremia is seriously underestimated in Chinese general medical patients: an observational retrospective study. BMC Nephrol 2017(1):18. DOI: 10.1186/s12882-017-0744-x.

8. Wald R, Jaber BL, Price LL, Upadhyay A, Madias NE. Impact of hospitalassociated hyponatremia on selected outcomes. Arch Intern Med 2010;170(3):294-302. DOI: 10.1001/archinternmed.2009.513.

9. Hyponatremia - Symptoms and causes. Mayo Clinic.

10. Pillai BP, Unnikrishnan AG, Pavithran PV. Syndrome of inappropriate antidiuretic hormone secretion: revisiting a classical endocrine disorder. Indian J Endocrinol Metab 2011;15(Suppl 3):S208-S215. DOI: 10.4103/2230-8210.84870.

11. Sahay M, Sahay R. Hyponatremia: a practical approach. Indian J Endocrinol Metab 2014;18(6):760. DOI: 10.4103/2230-8210.141320.

12. Anker NB, Cho KC. Hyponatremia. In: Papadakis MA, McPhee SJ, Rabow MW. Current Medical Diagnosis and Treatment 2020. New York, NY: McGraw-Hill Education; 2020.

13. Ball SG, lqbal Z. Diagnosis and treatment of hyponatraemia. Best Pract Res Clin Endocrinol Metab 2016;30(2):161-173. DOI: 10.1016/ j.beem.2015.12.001.

14. Renneboog B, Musch W, Vandemergel X, Manto MU, Decaux G. Mild chronic hyponatremia is associated with falls, unsteadiness, and attention deficits. Am J Med 2006;119(1):71.e1-8. DOI: 10.1016/ j.amjmed.2005.09.026.

15. Nguyen MK, Ornekian V, Butch AW, Kurtz I. A new method for determining plasma water content: application in pseudohyponatremia. Am J Physiol Renal Physiol 2007;292(5):F1652F1656. DOI: 10.1152/ajprenal.00493.2006.

16. Hillier TA, Abbott RD, Barrett EJ. Hyponatremia: evaluating the correction factor for hyperglycemia. Am J Med 1999;106(4):399-403. DOI: 10.1016/s0002-9343(99)00055-8.

17. Schrier RW. Body water homeostasis: clinical disorders of urinary dilution and concentration. J Am Soc Nephrol JASN 2006;17(7): 1820-1832. DOI: 10.1681/ASN.2006030240.

18. Adrogué HJ, Madias NE. Hyponatremia. N Engl J Med 2000;342(21): 1581-1589. DOI: 10.1056/NEJM200005253422107.

19. Adrogué HJ, Madias NE. The challenge of hyponatremia. J Am Soc Nephrol: JASN 2012;23(7):1140-1148. DOI: 10.1681/ASN.2012020128.

20. Tenny S, Thorell W. Cerebral Salt Wasting Syndrome, In:, StatPearls. Treasure Island (FL): StatPearls Publishing; 2020.

21. Ashraf N, Locksley R, Arieff Al. Thiazide-induced hyponatremia associated with death or neurologic damage in outpatients. Am J Med 1981;70(6):1163-1168. DOI: 10.1016/0002-9343(81)90822-6.

22. Spital A. Hyponatremia in adrenal insufficiency: review of pathogenetic mechanisms. South Med J 1982;75(5):581-585. DOI: 10.1097/00007611-198205000-00018.

23. Biswas $M$, Davies JS. Hyponatraemia in clinical practice. Postgrad Med J 2007;83(980):373-378. DOI: 10.1136/pgmj.2006.056515.

24. Frizelle FA, Colls BM. Hyponatremia and seizures after bowel preparation: report of three cases. Dis Colon Rectum 2005;48(2): 393-396. DOI: 10.1007/s10350-004-0778-6.

25. Diederich S, Franzen N-F, Bähr V, Oelkers W. Severe hyponatremia due to hypopituitarism with adrenal insufficiency: report on 28 cases. Eur J Endocrinol 2003;148(6):609-617. DOI: 10.1530/eje.0.1480609.

26. Karp BI, Laureno R. Pontine and extrapontine myelinolysis: a neurologic disorder following rapid correction of hyponatremia. Medicine (Baltimore) 1993;72(6):359-373. DOI: 10.1097/00005792199311000-00001.

27. Verbalis JG, Goldsmith SR, Greenberg A, Schrier RW, Sterns RH. Hyponatremia treatment guidelines 2007: expert panel recommendations. Am J Med 2007;120(11 Suppl. 1):S1-S21. DOI: 10.1016/j.amjmed.2007.09.001.

28. Furst H, Hallows KR, Post J, Chen S, Kotzker W, Goldfarb S, et al. The urine/plasma electrolyte ratio: a predictive guide to water restriction. In: American Journal of the Medical Sciences. . Lippincott Williams and Wilkins; 2000. 240-244. DOI: 10.1097/00000441-20000400000007.

29. Decaux G, Schlesser M, Coffernils M, Prospert F, Namias B, Brimioulle $\mathrm{S}$, et al. Uric acid, anion gap and urea concentration in the diagnostic approach to hyponatremia. Clin Nephrol 1994;42(2):102-108.

30. Musch W, Verfaillie L, Decaux G. Age-related increase in plasma urea level and decrease in fractional urea excretion: clinical application in the syndrome of inappropriate secretion of antidiuretic hormone. Clin J Am Soc Nephrol 2006;1(5):909-914. DOI: 10.2215/CJN. 00320106.

31. Decaux G, Musch W, Penninckx R, Soupart A. Low plasma bicarbonate level in hyponatremia related to adrenocorticotropin deficiency. J Clin Endocrinol Metab 2003;88(11):5255-5257. DOI: 10.1210/jc.2003030399.

32. Sterns RH, Nigwekar SU, Hix JK. The treatment of hyponatremia. Semin Nephrol 2009;29(3):282-299. DOI: 10.1016/j.semnephrol.2009.03.002.

33. Berl T. The Adrogue-Madias formula revisited. Clin J Am Soc Nephrol 2007;2(6):1098-1099. DOI: 10.2215/CJN.03300807.

34. Ganguli A, Mascarenhas RC, Jamshed N, Tefera E, Veis JH. Hyponatremia: Incidence, risk factors, and consequences in the elderly in a home-based primary care program. Clin Nephrol 2015;84(2):75-85. DOI: 10.5414/CN108453.

35. Agarwal SM, Agrawal A. A comparative study of the clinicoaetiological profile of hyponatremia at presentation with that developing in the hospital. Indian J Med Res 2011;134(7):118-122.

36. Shapiro DS, Sonnenblick M, Galperin I, Melkonyan L, Munter G. Severe hyponatraemia in elderly hospitalized patients: prevalence, aetiology and outcome. Intern Med J 2010;40(8):574-580. DOI: 10.1111/j.14455994.2010.02217.x. 
37. Gill G, Huda B, Boyd A, Skagen K, Wile D, Watson I, et al. Characteristics and mortality of severe hyponatraemia - a hospital-based study. Clin Endocrinol (Oxf) 2006;65(2):246-249. DOI: 10.1111/j.13652265.2006.02583.x.

38. Hoorn EJ, Lindemans J, Zietse R. Development of severe hyponatraemia in hospitalized patients: treatment-related risk factors and inadequate management. Nephrol Dial Transplant 2006;21(1):70-76. DOI: 10.1093/ndt/gfi082.

39. Kutz A, Ebrahimi F, Sailer CO, Wagner U, Schuetz P, Mueller B, et al. Seasonality of hypoosmolar hyponatremia in medical inpatientsdata from a nationwide cohort study. J Clin Endocrinol Metabol 2020;105(4):dgz320. DOI: 10.1210/clinem/dgz320.
40. Annane D, Decaux G, Smith N. Efficacy and safety of oral conivaptan a vasopressin-receptor antagonist, evaluated in a randomized, controlled trial in patients with euvolemic or hypervolemic hyponatremia. Am J Med Sci 2009;337(1):28-36. DOI: 10.1097/ MAJ.0b013e31817b8148.

41. Gerbes AL, Gülberg V, Ginès $P$, Decaux $G$, Gross $P$, Gandjini $H$, et al. Therapy of hyponatremia in cirrhosis with a vasopressin receptor antagonist: a randomized double-blind multicenter trial. Gastroenterology 2003;124(4):933-939. DOI: 10.1053/gast.2003.50143.

42. Peri A. Management of hyponatremia: causes, clinical aspects, differential diagnosis and treatment. Expert Rev Endocrinol Metabol 2019;14(1):13-21. DOI: 10.1080/17446651.2019.1556095. 